\title{
SISTEM INFORMASI SURAT KETERANGAN PENDAMPING IJAZAH (SKPI) BERBASIS WEB PADA KAMPUS $X$
}

\author{
Fikri Zufri*, Tina Tri Wulansari, Riyayatsyah \\ Program Studi Sistem Informasi, Universitas Mulia PSDKU Samarinda, Indonesia
}

*fikri@student.spb.ac.id

\begin{abstract}
In making the information system of diploma companion certificate (SKPI) BAAK Campus X there was a pile up of files to overcome these problems, so a certificate of companion certificate information system (SKPI) was made on Campus X based on website.. The System Development Method used in this thesis is the Prototype Method while the tool used in the development of the thesis system is Flowchart, FOD, CD, DFD, Relationship Tables and table structure as well as Making a system using the PHP Programming language and MySQL database management system Beta test results show that 67\% of respondents said that this system fulfills 9 criteria for a good website. $100 \%$ of respondents (BAAK administrators) said that this system helped BAAK work. (FZ).
\end{abstract}

Keywords: Information Systems, Web-Based, Certificate of Companion Diploma, PHP, MySQL Database Management System.

Abstrak

Dalam pembuatan sistem informasi surat keterangan pendamping ijazah (SKPI) BAAK Kampus X terjadi penumpukan berkas-berkas untuk mengatasi permasalahan tersebut maka dibuatlah sistem informasi surat keterangan pendamping ijazah (SKPI) di Kampus X berbasis website. Metode Pengembangan Sistem yang digunakan skripsi ini adalah Metode Prototype sedangkan Alat bantu yang digunakan dalam pengembangan sistem skripsi adalah Flowchart, FOD, CD, DFD, relasi tabel dan struktur tabel serta Pembuatan sistem menggunakan bahasa Pemrograman PHP dan Database Management System MySQL Hasil pengujian Beta menunjukkan bahwa $67 \%$ responden mengatakan bahwa sistem ini memenuhi 9 kriteria situs web yang baik. 100\% responden (administrator BAAK) mengatakan bahwa sistem ini membantu pekerjaan BAAK. (FZ).

Kata kunci: Sistem Informasi, Berbasis Web, Surat Keterangan Pendamping Ijazah, PHP, Database Management System MySQL.

\section{Pendahuluan}

Kementerian Pendidikan dan Kebudayaan mengeluarkan peraturan pemerintah nomor 81 tahun 2014 tentang ijazah, sertifikat profesi dan sertifikat kompetensi perguruan tinggi. Dalam pasal 1 ayat 4 PP nomor 81 tahun 2014 disebutkan bahwa surat keterangan pendamping ijazah yang disingkat dengan SKPI merupakan dokumen yang memuat informasi tentang capaian akademik atau kualifikasi dari pendidikan tinggi bergelar [1].

Kampus pembuatan data kompetensi seperti Ijazah, Transkrip, SKPI, dan lain-lain yang awalnya dibuat oleh bagian Program Studi (Prodi) Manajemen Kampus X diserahkan kepada bagian Biro Administrasi Akademik dan Kemahasiswaan (BAAK) untuk mencetakkan seluruh data kompetensi. dalam pembuatan SKPI bagian BAAK mendapatkan kesulitan data tentang kompetensi calon lulusan, hal ini menjadi faktor utama yang dihadapi Kampus X dalam mengeluarkan SKPI. Kampus X yang sudah menggunakan SKPI itu pun pengolahan datanya masih bersifat belum terkomputerisasi, sistem yang berjalan pada mahasiswa Kampus X , mahasiswa mengisi formulir secara tertulis menyebabkan lambatnya proses pengumpulan informasi dan data, terjadi kehilangan form yang diberikan serta penumpukan pada loket dan berkas, kondisi ini menjadi kerugian sendiri bagi Kampus X terutama calon lulusan.

Untuk mengatasi penumpukan berkasberkas keperluan pembuatan SKPI maka diperlukan sistem informasi sebagai suatu komponen yang terdiri dari manusia, 
teknologi informasi, dan prosedur kerja yang memproses, menyimpan, menganalisis, dan menyebarkan informasi untuk mencapai suatu tujuan [2]. Pada Kampus X bagian BAAK khususnya pada pembuatan SKPI.

\section{Metoda Penelitian}

\subsection{Metode Pengembangan Sistem}

Penelitian ini menggunakan metode prototype persyaratan untuk pembuatan sistem informasi SKPI berbasis web Kampus $\mathrm{X}$ . Untuk alat bantu yang digunakan dalam tahap pengembangan sistem ini adalah Site Maps untuk menggambarkan isi per halaman sistem Bagan Alir (Flowchart) [3] untuk urutan proses kegiatan agar menjadi lebih jelas, penjelasan lebih detail tentang site maps dan flowchart adalah sebagai berikut:

1. Bagan Alir Dokumen/Flow of Document (FOD)

2. Diagram Konteks (Context Diagram)

3. Diagram Aliran Data/Data Flow Diagram (DFD)

4. Entity Relationship Diagram (ERD)

5. Site Maps

6. Hierarchy Input Process Output (HIPO)

Prototype persyaratan dikembangkan sebagai satu cara untuk mendefinisikan persyaratan-persyaratan fungsional dari sistem baru ketika pengguna tidak mampu mengungkapkan dengan jelas apa yang mereka inginkan [4].

Dengan meninjau prototype persyaratan seiring dengan ditambahkannya fitur-fitur, pengguna akan mampu mendefinisikan pemrosesan yang dibutuhkan dari sistem yang baru. Ketika persyaratan ditentukan, prototype persyaratan telah mencapai tujuannya dan proyek lain akan dimulai untuk mengembangkan sistem baru.

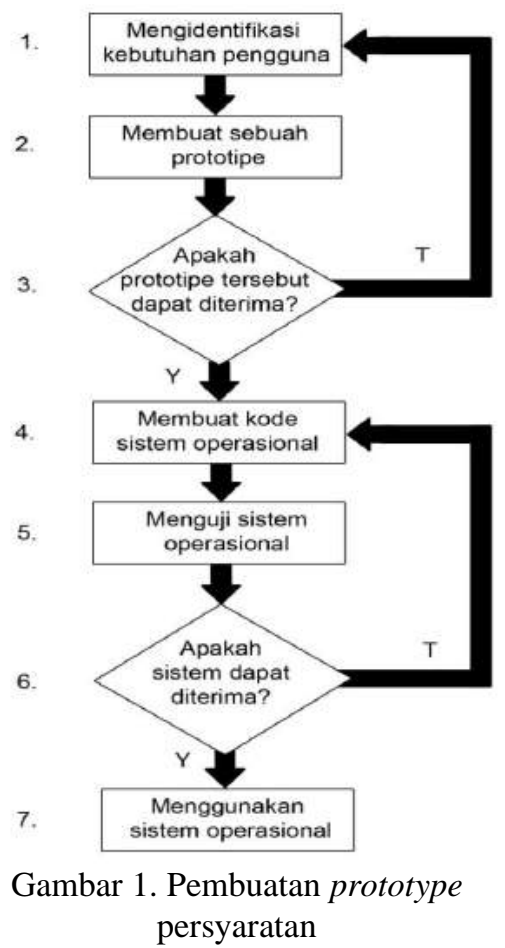

Langkah-langkah berikutnya adalah sebagai berikut:

1 Mengidentifikasi kebutuhan pengguna.

2 Membuat sebuah prototype.

3 Menentukan apakah prototype diterima.

Pengguna memberitahukan kepada

pengembang apakah sistem dapat

diterima. Jika ya, maka akan diteruskan

ke langkah selanjutnya

4 Membuat kode sistem informasi baru.

5 Menguji sistem operasional

6 Menentukan apakah sistem diterima.

Jika ya, maka akan diteruskan ke

langkah selanjutnya

7 Menggunakan sistem operasional

Untuk menyatakan bahwa metodemetode pengujian di antaranya adalah metode white-box, basis path, struktur kontrol, black- box juga pengujian alpha dan beta, dengan penjelasan bahwa metodemetode pengujian di antaranya adalah metode white-box, basis path, struktur kontrol, black- box juga pengujian alpha dan beta, dengan penjelasan metode tersebut adalah:

1) White-Box

2) Basis path

3) Struktur Kontrol.

4) Black-Box 


\section{5) Pengujian Alpha dan Beta}

Maka dari itu dalam tahap untuk pengujian diperlukannya suatu proses eksekusi suatu program, dilakukan secara sukses (sesuai dengan sasaran tersebut) maka tidak akan ditemukan kesalahan di dalam perangkat lunak [5].

\section{Hasil dan Pembahasan}

\subsection{Pemodelan Sistem}

Pada bagian ini, penulis membahas hasil analisis dan perancangan, implementasi, dan pengujian prototype yang diusulkan sebagai berikut :

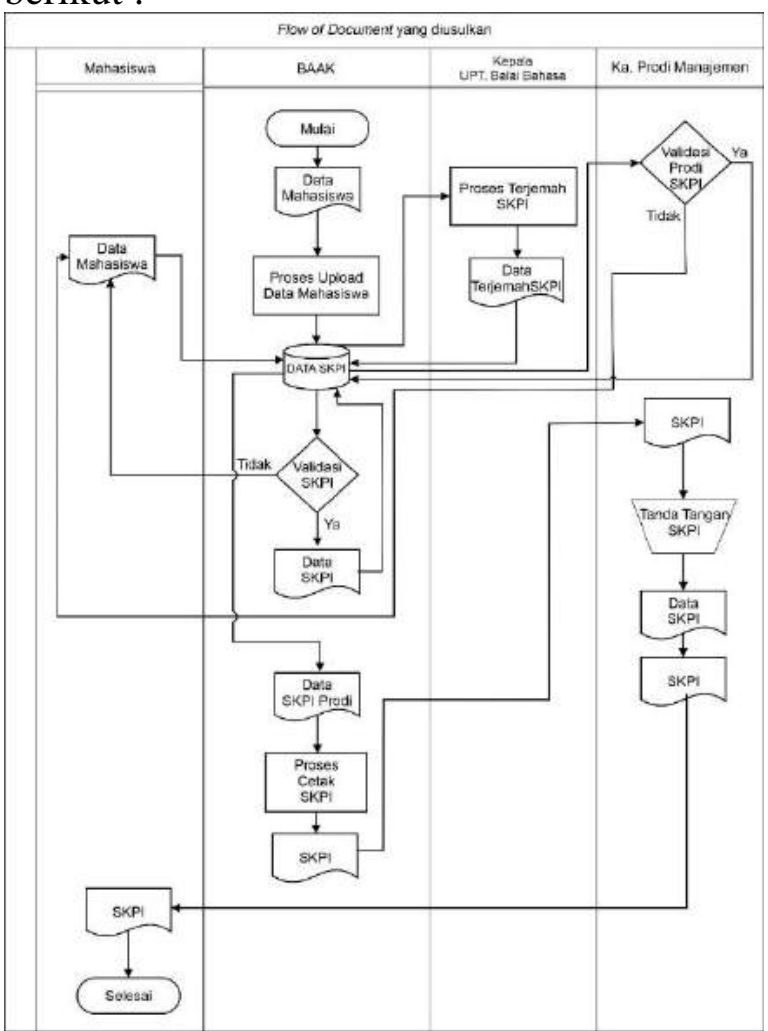

Gambar 2. Flow of Document yang diusulkan

Flow Of Document yang diusulkan menjelaskan tentang alur yang memungkinkan untuk menggambarkan sistem [6] pelayanan Surat Keterangan Pendamping Ijazah (SKPI) yang diusulkan pada BAAK STIE Samarinda. Alur Pelayanan pada Surat Keterangan Pendamping Ijazah (SKPI) BAAK memiliki empat (4) entitas terdiri dari entitas mahasiswa, BAAK, kepala bagian UPT, dan kepala Program Studi. Alur pelayanan dimulai dari entitas BAAK mengunggah data mahasiswa dari SIA, dilanjutkan dengan memasukkan data program studi, data organisasi, data pendidikan karakter setelah selesai memasukkan data-data BAAK memberitahu kepada mahasiswa melalui email kampus mahasiswa bahwa SKPI sudah bisa dibuat. Entitas mahasiswa mendapatkan user dan password entitas mahasiswa tersebut login dengan menggunakan user mahasiswa untuk menggubah biodata mahasiswa, memasukkan data juara/kompetensi jika ada, data organisasi yang pernah diikuti jika ada, data skripsi/tugas akhir, data pendidikan karakter jika ada, data tempat magang jika ada, dan data skor TOEFL. Selanjutnya kembali ke entitas BAAK yang bertugas untuk memvalidasi data yang telah di input oleh mahasiswa. Setelah entitas BAAK memvalidasi, dilanjutkan dengan entitas Kepala UPT. Balai Bahasa untuk menerjemahkan data SKPI ke dalam bahasa Inggris kemudian memvalidasinya.

Selanjutnya entitas Kepala Program Studi melakukan validasi untuk masingmasing mahasiswa tiap program studi yang berhak mendapatkan SKPI. Setelah Program Studi melakukan validasi pengecekan data kembali ke entitas BAAK untuk memproses pencetakan Surat Keterangan Pendamping Ijazah (SKPI) dan menyerahkan Surat Keterangan Pendamping Ijazah (SKPI) kepada entitas mahasiswa.

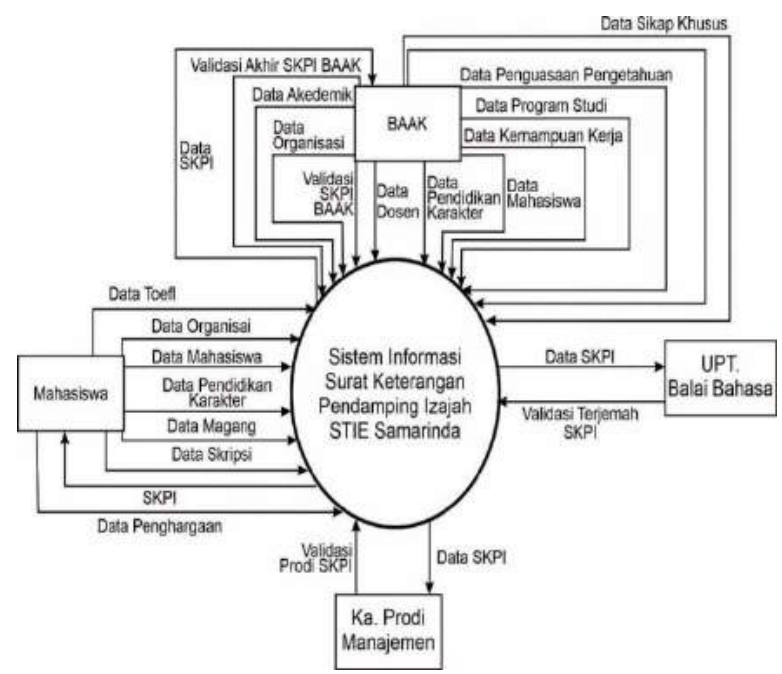

Gambar 3. Context Diagram

Pada Gambar 3 terdapat 4 external entity yang melakukan kegiatan pengelolaan di dalam sistem, setidaknya ada 14 data yang diinput, 3 jenis output dalam bentuk sistem dan 1 jenis dokumen output yang dihasilkan 
dalam sistem informasi Surat Keterangan Pendamping Ijazah (SKPI) ini.

Berdasarkan Context Diagram di atas diperoleh beberapa proses yang adakan di jelaskan pada Data Flow Diagram Level 0 secara detail. Adapun Data Flow Diagram level 0 dapat dilihat pada Gambar 4 sebagai berikut:

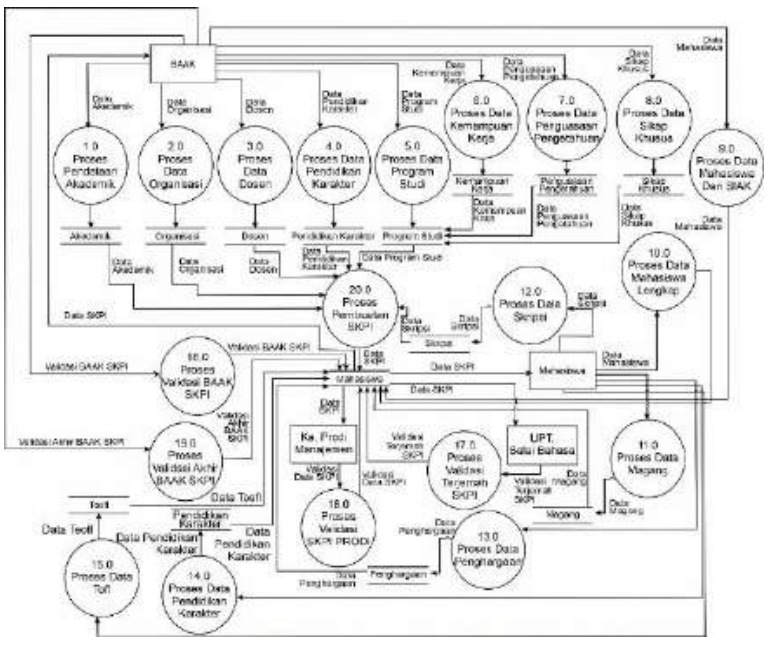

Gambar 4 Data Flow Diagram (DFD) level 0

Pada Gambar 4 menerangkan bahwa terdapat 20 proses data yang digambarkan di dalam level data flow diagram ini, dimana terdapat 1 proses yang menghasilkan feedback yang digambarkan DFD level 0 pada Gambar 6.

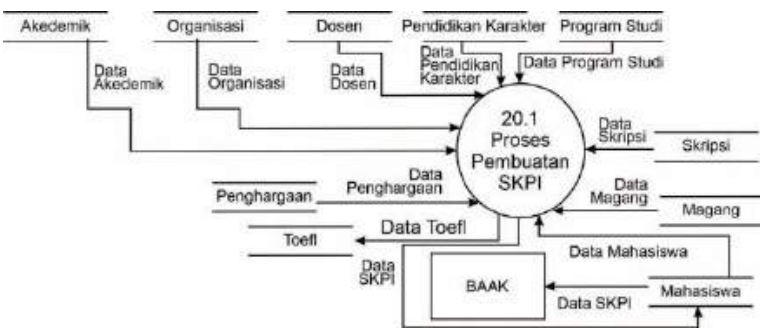

Gambar 5. Data Flow Diagram (DFD) level 1 proses cetak SKPI

Adapun pada Gambar 5 menerangkan proses pengambilan data yang dibutuhkan untuk menghasilkan output yaitu berupa hasil cetak SKPI mahasiswa yang telah di validasi oleh BAAK, UPT. Balai Bahasa dan Program Studi selama satu semester.

Berdasarkan data flow diagram level 0 terdapat 20 proses di mana terdapat 14 penyimpanan data atau file yang akan dijelaskan pada Entity Relationship Diagram (ERD), Entity Relationship Diagram (ERD), pada Gambar 6 menerangkan bawah terdapat 13 tabel yaitu:

1) Tabel mahasiswa,

2) Tabel pendidikan karakter,

3) Tabel skripsi,

4) Tabel dosen,

5) Tabel akademik,

6) Tabel magang,

7) Tabel TOEFL,

8) Tabel penghargaan,

9) Tabel organisasi,

10) Tabel prodi

11) Tabel kemampuan kerja,

12) Tabel sikap khusus,

13) Tabel penguasaan pengetahuan.

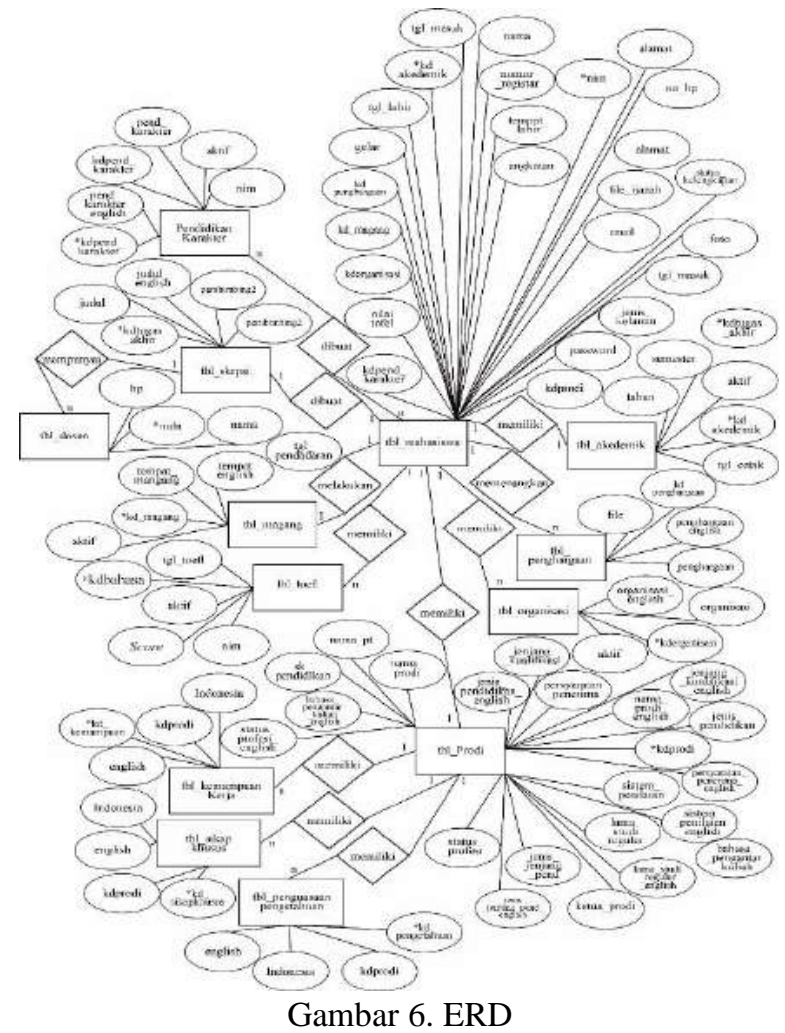

Pada tabel di atas terdapat relasi tabel antara lain, tabel mahasiswa mempunyai 8 relasi dengan tabel program, tabel organisasi, tabel penghargaan, tabel magang dan tabel skripsi, tabel skripsi dengan tabel dosen, serta relasi antara tabel prodi, yang memilik 3 relasi antara lain tabel mahasiswa, tabel sikap khusus, tabel kemampuan kerja, dan penguasaan pengetahuan.

Structure Database dimaksudkan untuk mengidentifikasi kebutuhan tabel yang diperlukan di dalam membangun sistem, adapun tabel-tabel yang dibutuhkan sebagai berikut: 
1) Tabel Mahasiswa

2) Tabel Organisasi

3) Tabel Pendidikan Karakter

4) Tabel Dosen Pembimbing

5) Tabel Tempat Magang/KKP/PI

6) Tabel Penghargaan/Kompetensi

7) Tabel Judul Skripsi/Tugas Akhir

8) Tabel TOEFL

9) Tabel Kemampuan Kerja

10) Tabel Sikap Khusus

11) Tabel Penguasaan Pengetahuan

12) Tabel Identitas Program Studi

13) Tabel Tahun Akademik

14) Tabel User

15) Tabel Pivot (bantu) Data Organisasi Mahasiswa

16) Tabel Pivot (bantu) Data Pendidikan Karakter Mahasiswa

Tampilan Website yang dibuat terdiri dari tampilan untuk halaman mahasiswa (user), staf BAAK, UPT. Balai Bahasa, dan Program Studi sebagai berikut:

1) Tampilan Login

Tampilan login akan tampil pada saat pertama kali aplikasi dijalakan, terdapat field username dan password, pengguna dapat memasukkan username dan password sesuai data yang telah di masukan dalam sistem.

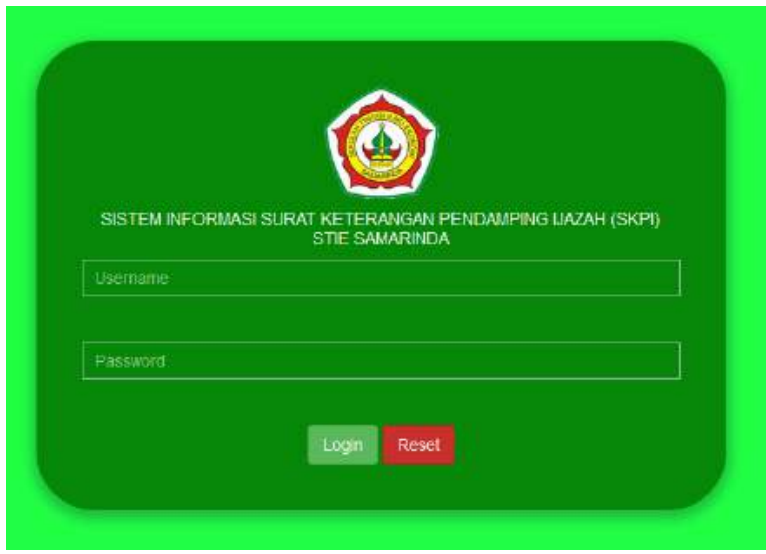

Gambar 7. Tampilan Login

2) Tampilan Halaman Mahasiswa

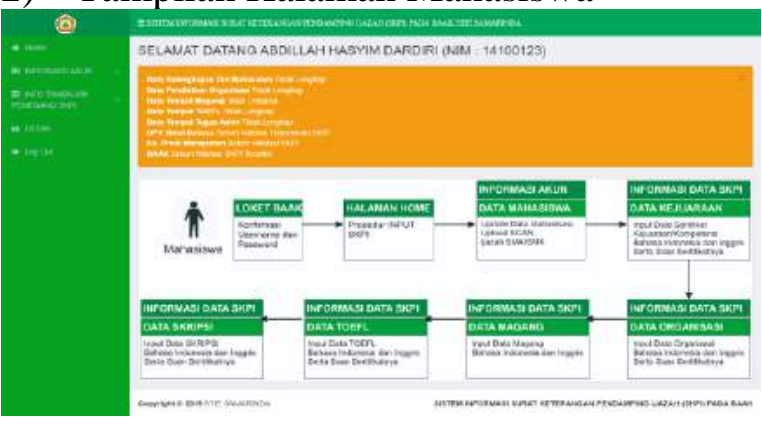

Gambar 8. Tampilan halaman mahasiswa

Adapun tampilan dari halaman mahasiswa dapat dilihat pada gambar 8 di atas:

Pada gambar 8 Tampilan halaman mahasiswa akan diberikan akses untuk mengubah biodata mahasiswa, mengisi data kejuaraan/kompetensi, mengisi data pengalaman organisasi, mengisi data pendidikan karakter, skor TOEFL, tempat magang KKP/PI, judul skripsi/tugas akhir.

3) Tampilan Halaman Edit Mahasiswa

Adapun tampilan dari halaman edit mahasiswa dapat dilihat pada gambar 10 sebagai berikut:

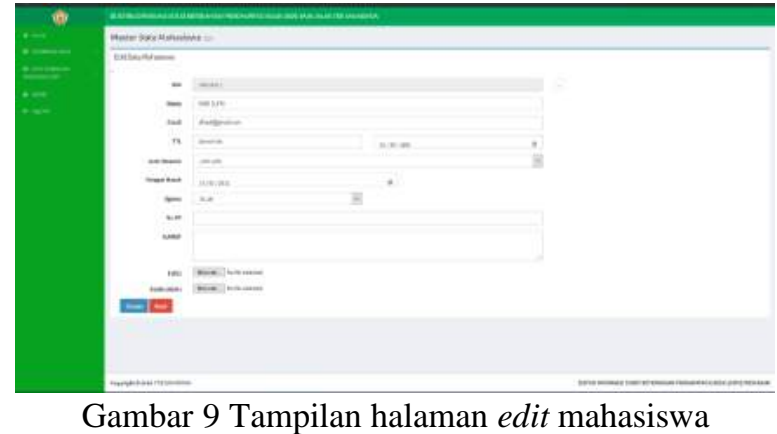

Pada Gambar 9 Tampilan halaman edit pengguna tampilan halaman edit data mahasiswa terdapat field untuk mengedit nama sesuai ijazah, email, tempat dan tanggal lahir, jenis kelamin, tanggal masuk, agama, no handphone dan alamat. Selain itu terdapat juga tombol browse pada foto untuk mengunggah foto mahasiswa, dan tombol browse pada scan ijazah untuk mengunggah scan ijazah. Kemudian terdapat tombol simpan untuk menyimpan data mahasiswa yang telah di edit, juga tombol reset untuk mengulang kembali pengeditan.

4) Tampilan Halaman Input Penghargaan/

Kompetensi Mahasiswa

Adapun Tampilan dari halaman input penghargaan/kompetensi mahasiswa dapat dilihat pada Gambar 11 sebagai berikut: 


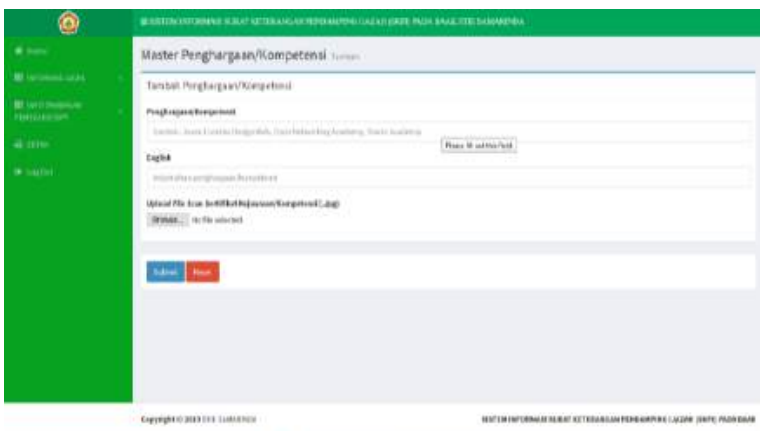

Gambar 10. Halaman input penghargaan/ kompetensi mahasiswa

Pada Gambar 10 tampilan halaman input penghargaan/kompetensi mahasiswa, kolom pertama untuk memasukkan data penghargaan/kompetensi dalam bahasa Indonesia, dan kolom kedua memasukkan data penghargaan/kompetensi dalam bahasa inggris. Selain itu terdapat juga tombol browse untuk mengunggah file scan sertifikat penghargaan/kompetensi. Juga terdapat tombol simpan untuk menyimpan data penghargaan/kompetensi dan tombol reset untuk mengosongkan semua form.

5) Tampilan Halaman Data Penghargaan/ Kompetensi Mahasiswa

Adapun tampilan dari halaman data penghargaan/kompetensi mahasiswa dapat dilihat pada Gambar 11 sebagai berikut:

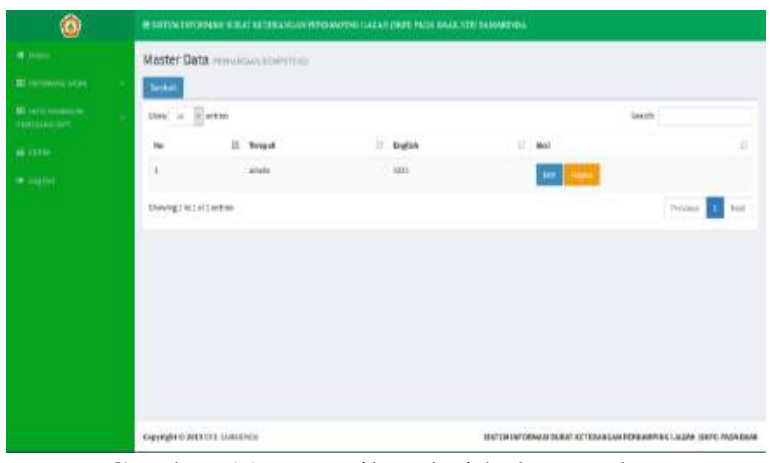

Gambar 11. Tampilan dari halaman data penghargaan/kompetensi mahasiswa

Pada Gambar 11 tampilan halaman data penghargaan/kompetensi mahasiswa terdapat field nama tempat dalam bahasa Indonesia dan bahasa Inggris, serta terdapat tombol edit untuk mengedit dan hapus data dari penghargaan/kompetensi mahasiswa.

6) Tampilan Halaman BAAK

Adapun rancangan tampilan dari halaman BAAK dapat dilihat pada Gambar 12 sebagai berikut :

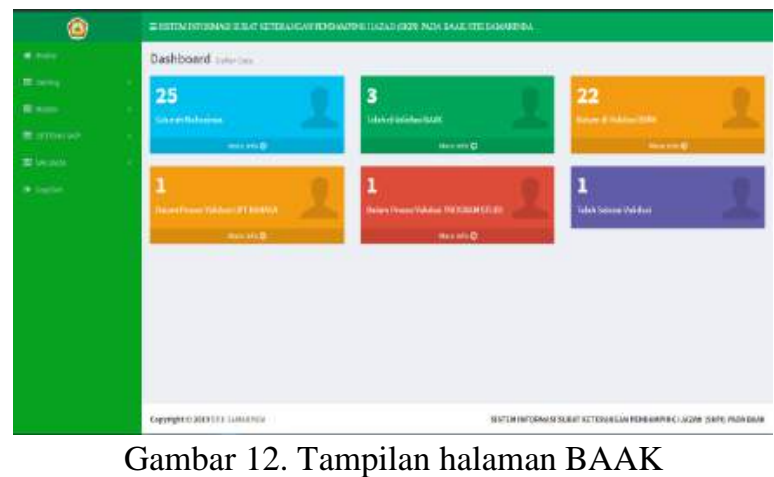

Pada Gambar 12 tampilan halaman BAAK akan diberikan akses untuk menambah pengguna, reset password, memasukkan master mahasiswa, master dosen, master organisasi, master program studi, master pendidikan karakter, memvalidasi data SKPI, menampilkan tabel validasi UPT. Balai bahasa, menampilkan validasi program studi, dan mencetak SKPI.

7) Tampilan Halaman Data Identitas Pemegang SKPI

Tampilan halaman data identitas pemegang SKPI terdapat field nim mahasiswa, nama mahasiswa, program studi, tanggal masuk, tanggal lulus, kelengkapan, dan terdapat tombol edit untuk mengubah kelengkapan data mahasiswa serta tombol detail untuk melihat detail kelengkapan data mahasiswa. Tampilan data identitas pemegang SKPI dapat dilihat pada Gambar 13 sebagai berikut:

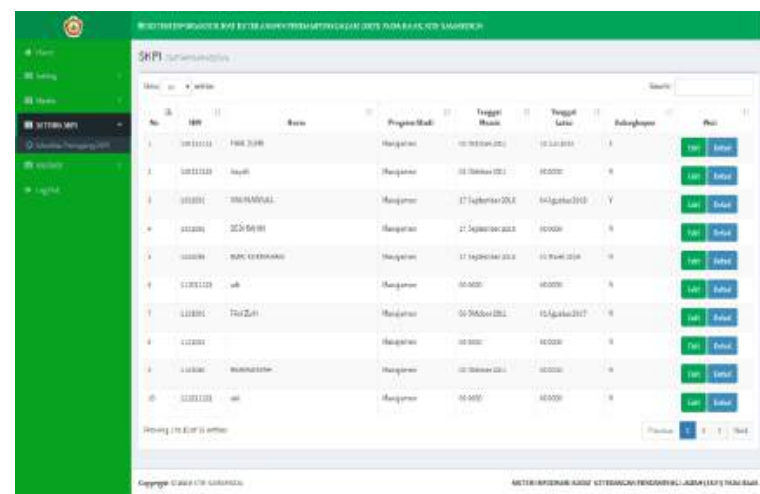

Gambar 13 Tampilan halaman data identitas

$$
\text { pemegang SKPI }
$$

\section{8) Pengujian Beta Testing}

Pada bagian ini pengembang melakukan pengujian kembali dengan metode black box terlebih dahulu sebelum demo program secara offline kepada pemilik, dengan tujuan agar tidak terjadi kesalahan yang tidak diinginkan. 
Pengujian sistem menggunakan pengujian beta testing [4] berdasarkan data hasil kuesioner, presentasi masing-masing jawaban dengan menggunakan rumus pada gambar 15:

$$
Y=\frac{\Sigma(\mathrm{N} . \mathrm{R})}{\text { Skor Ideal }} \times 100 \%
$$

Gambar 15 Rumus pengujian Beta

Dalam penyebaran kuesioner penulis menggunakan skala likert dengan menggunakan 5 titik respons yaitu sangat setuju, setuju, tidak memutuskan, tidak setuju, dan sangat tidak setuju [7] yang kemudian diberikan kepada 10 orang responden untuk pengujian beta testing berupa pertanyaan yang berkaitan tentang 9 kriteria website yang baik, bertujuan untuk mengetahui sejauh mana kualitas dan apakah website yang dibuat sudah termasuk website yang baik:

\begin{tabular}{|c|c|c|c|c|c|}
\hline \multirow[t]{2}{*}{ No } & \multirow[t]{2}{*}{ Aspek-Aspek } & \multicolumn{4}{|c|}{ Jawaban } \\
\hline & & SS & $\mathbf{S}$ & TS & STS \\
\hline 1 & $\begin{array}{l}\text { Apakah sistem informasi } \\
\text { Keterangan Pendamping Ijazah } \\
\text { dimengerti/dipelajari? }\end{array}$ & 7 & 3 & & \\
\hline 2 & $\begin{array}{l}\text { Penyusunan tata letak informasi dalam } \\
\text { sistem informasi Surat keterangan } \\
\text { Pendamping Ijazah ini tepat }\end{array}$ & 6 & 4 & & \\
\hline 3 & $\begin{array}{l}\text { Teks dalam Sistem informasi Surat } \\
\text { Keterangan Pendamping Ijazah ini dapat } \\
\text { dibaca dengan jelas }\end{array}$ & 9 & 1 & & \\
\hline 4 & $\begin{array}{l}\text { Apakah konten informasi sesuai dengan } \\
\text { sistem informasi Surat keterangan } \\
\text { Pendamping Ijazah ini bermanfaat }\end{array}$ & 2 & 6 & 2 & \\
\hline 5 & $\begin{array}{l}\text { Apakah Sistem informasi } \text { Surat } \\
\text { Keterangan Pendamping Ijazah dapat } \\
\text { diakses di semua device }\end{array}$ & 9 & 1 & 0 & \\
\hline 6 & $\begin{array}{l}\text { Bagaimana Kecepatan website waktu } \\
\text { memasuki halaman awal/ home dalam } \\
\text { Sistem informasi Surat Keterangan } \\
\text { Pendamping Ijazah }\end{array}$ & 8 & 2 & 0 & \\
\hline 7 & $\begin{array}{l}\text { Apakah fungsi-fungsi dalam sistem Surat } \\
\text { Keterangan Pendamping Ijazah ini } \\
\text { berjalan }\end{array}$ & 8 & 1 & 1 & \\
\hline 8 & $\begin{array}{l}\text { Bagaimana Kemudahan dalam membaca } \\
\text { informasi atau tulisan sistem informasi } \\
\text { Surat Keterangan Pendamping Ijazah } \\
\text { berialan dengan baik }\end{array}$ & 5 & 5 & & \\
\hline 9 & $\begin{array}{l}\text { Bagaimana Kemudahan berinteraksi dan } \\
\text { tingkat bantuan yang diberikan oleh } \\
\text { Sistem Informasi Surat Keterangan } \\
\text { Pendamping Ijazah }\end{array}$ & 5 & 5 & & \\
\hline & TOTAL & 59 & 28 & 3 & \\
\hline
\end{tabular}

Gambar 15. Kuesioner

Total Skor $=($ Total pemilih terbanyak $\times$ Skor $)+($ total terendah $\times$ skor $)=$ Total Skor $=$ $(59 \times 4)+(3 \times 2)=$ Total Skor $=242$.

Skor tertinggi $=($ nilai tertinggi $\times$ jumlah pertanyaan $\times$ jumlah responden $)=(4 \times 9 \times 10)$ Skor tertinggi $=360$.

Rumus index $\%=$ (total skorskor) $/$ tertinggi $\times 100 \%=242 / 360 \times 100 \%=67$ $\%$.
Dari perhitungan di atas maka dapat diujikan hipotesis sebagai berikut:

$\mathrm{HO}$ : responden sistem informasi SKPI memiliki hasil presentasi dari di bawah skor ideal yaitu $40 \%$.

$\mathrm{H} 1$ : pengguna sistem informasi SKPI memiliki hasil presentasi di atas skor ideal yaitu $40 \%$.

Berdasarkan perolehan hasil pengujian beta pembuatan sistem informasi SKPI pada Kampus X menghasilkan nilai responden yaitu 67\% maka hipotesis diterima, hal ini menunjukkan bawah pengguna sistem informasi SKPI dapat digunakan untuk pembuatan SKPI pada kampus X .

\section{Kesimpulan}

Berdasarkan uraian dari masing-masing bab dan hasil pembahasan maka penulis dapat mengambil kesimpulan sebagai berikut:

1. Sistem dibangun dengan menggunakan bahasa pemrograman PHP, dan database management system MySQL [8] yang digunakan dalam mengimplementasikan Sistem Informasi Surat Keterangan Pendamping Ijazah (SKPI).

2. Metode untuk membuat Sistem informasi Surat Keterangan Pendamping Ijazah (SKPI) dengan menggunakan metode Prototype Persyaratan.

3. Dengan adanya Sistem informasi Surat Keterangan Pendamping Ijazah pada STIE Samarinda ini dapat memudahkan BAAK dalam pencetakan SKPI mahasiswa.

4. Hasil pengujian Sistem informasi Surat Keterangan Pendamping Ijazah (SKPI) Hasil pengujian Beta menunjukkan bahwa $67 \%$ responden mengatakan bahwa sistem ini memenuhi 9 kriteria situs web yang baik. $100 \%$ responden (administrator BAAK) mengatakan bahwa sistem ini membantu pekerjaan BAAK

\section{Saran}

Dari pembahasan dan kesimpulan maka penulis memberikan saran sebagai berikut:

1. Diharapkan untuk pengembangan sistem ini selanjutnya bisa menambahkan pengamanan sistem karena pengamanan sistem yang dibuat masih dirasa kurang. 
2. Penambahan fitur chat atau pesan agar mahasiswa yang tidak berada di kampus dapat menanyakannya ke staf BAAK.

3. Menambahkan fitur lain untuk melengkapi dan mempermudah tugas BAAK yang lain seperti penambahan syarat-syarat wisuda bagi mahasiswa.

\section{Daftar Pustaka}

[1] Permendikbud, "PERATURAN MENTERI PENDIDIKAN DAN KEBUDAYAAN NOMOR 21 TAHUN 2016 TENTANG STANDAR ISI PENDIDIKAN DASAR DAN MENENGAH,” Rev. Bras. Ergon., 2016.

[2] R. E. Indrajit, "Manajemen sistem informasi dan teknologi informasi," $P T$ Elek Media Komputindo, Jakarta, 2001.

[3] Subhan, "Pengertian Perancangan Sistem Informasi," 07/2012. 2012.

[4] A. Kadir, S. Sarosa, R. Mcleod, G. P. Schell, R. Martono, and S. Mulyani, "Practical Inventory Management," Am. Enterp. Inst. Public Policy Res., 2008.

[5] R. S. Pressman, Rekayasa Perangkat Lunak: Pendekatan Praktisi. 2010.

[6] S. Paijo, ILMU DAN APLIKASI PENDIDIKAN Bagian I: Ilmu Pendidikan Teoretis. 2007.

[7] W. Budiaji, "Skala Pengukuran dan Jumlah Respon Skala Likert," J. Ilmu Pertan. dan Perikan., 2013.

[8] A. R. K. Lena, "Pengertian PHP dan MySQL," Ilmu Teknol. Inf., 2015. 